To the Editors:

\title{
First successful in vitro culture of Leishmania sp. causing autochthonous visceral leishmaniasis in Sri Lanka
}

\author{
Ceylon Medical Journal 2011; 56: 179-180
}

The first autochthonous case of visceral leishmaniasis (VL) in Sri Lanka was reported in 2007 [1], more than a decade after the first report of autochthonous cutaneous leishmaniasis (CL) in 1992 [2]. Since 2007 only three endemic patients with confirmed VL was reported from the country (two from the Anuradhapura district), and the current report is on the third patient (from the Vavuniya district). Few cases of mucocutaneous leishmaniasis (MCL) have been reported in the country to date $[3,4]$. However, thus far successful in vitro culture of the Leishmania parasite could be carried out only in the strains giving rise to cutaneous leishmaniasis [5]. We report the first successful in vitro culture of Leishmania sp. causing endogenous VL in Sri Lanka.

A diagnostic bone marrow aspiration was carried out in a 57-year old male from Vavuniya district who presented with pyrexia of unknown origin of 6 months duration. There was no history of overseas travel, but he had an occupational history of being in the jungle as a civil soldier for many months in the Vavuniya district during the NorthEast civil war immediately prior to occurrence of symptoms. The patient was pale but he had no generalised lymphadenopathy. He had a moderate, firm hepatosplenomegaly. The bone marrow aspiration contained numerous Leishmania amastigotes (Figure 1a). The trephine biopsy showed the typical dot and dash appearance of Leishman donovan (LD) bodies (Figure 1b).

A few drops from the same bone marrow aspirate were inoculated into medium 199 supplemented with $10 \%$ FBS, $200 \mathrm{mM}$ glutamine, $25 \mathrm{mM}$ adenosine, folic acid 10 $\mathrm{mg} / \mathrm{ml}$ and penicillin/streptomycin $100 \mu \mathrm{l} / \mathrm{ml}$. The cultures were maintained at $24^{\circ} \mathrm{C}$. First bone marrow culture was sub-cultured 3 days after inoculation to eliminate the action of bone marrow inhibitory factors on the growing promastigotes.

The original cultures showed a promastigote count of $1 \times 10^{4} / \mathrm{ml}$ five weeks after the first inoculation. The first subculture inoculated 3 days after the first inoculation showed a promastigote count of $7 \times 10^{4} / \mathrm{ml}$ five weeks after inoculation (Figure 1c).

Though endogenous cases of cutaneous, mucocutaneous and visceral forms of leishmaniasis are being reported in the country, the sandfly vector is yet to be identified. Few reports show the dog as a possible reservoir host of leishmaniasis in Sri Lanka [6, 7]. However, in India, humans are the only reservoir host for VL (Kala- azar) [8]. The patient reported in this study had close contact with the jungle, raising the question of the existence of a possible sylvatic cycle for VL in Sri Lanka in contrast to the disease pattern that is seen in India.

The success of in vitro culture of the strain causing VL in Sri Lanka will pave the way for the identification of the Leishmania parasite to species and strain level. The strain identification will be carried out by performing isoenzyme studies which is the gold standard for Leishmania strain identification [8]. This early success of in vitro culture of the Leishmania parasite causing visceral leishmaniasis and possible strain identification in the near future will have a bearing on understanding of the disease pattern of VL in Sri Lanka, and will enable us to implement adequate preventive measures.

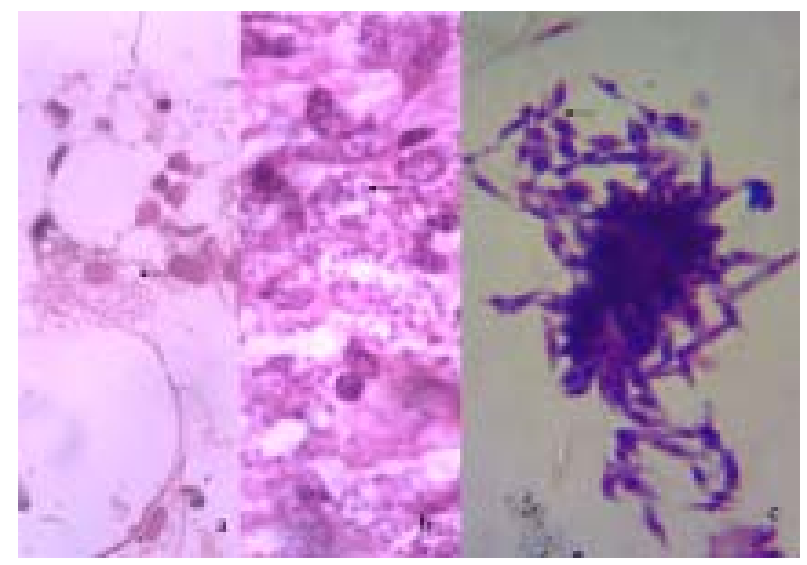

Figure 1a. Bone marrow aspiration showing numerous amastigotes within a histiocyte (Leishman, 40x). Figure 1b. Trephine biopsy showing LD bodies (H \& E, 100x).

Figure 1c. First in vitro subculture of bone marrow aspirate with the promastigotes (Geimsa 100x).

\section{Acknowledgements}

We thank Professor Greg Matlashewski, Programme Leader: Virology/Parasitology, Research for the Elimination of Visceral Leishmaniasis, Tropical Diseases Research (TDR), World Health Organization and Dr. Wen Wei Zhang from the McGill University, Montreal, Canada, for supplying us with the culture medium and guidance in establishing the in vitro Leishmania culture, Mrs. Indira Athauda for the photographs and the University of Sri Jayewardenepura Research Grant ASP/06/RE/2008/03 for funding. 


\section{References}

1. Abeygunasekara PH, Costa YJ, Seneviratne N, Ratnatunga $\mathrm{N}$, Wijesundera M de S. Locally acquired visceral leishmaniasis in Sri Lanka. The Ceylon Medical Journal 2007; 52: $30-1$.

2. Athukorale DN, Seneviratne JK, Ihalamulla RL, Premaratne UN. Locally acquired cutaneous leishmaniasis in Sri Lanka. Journal of Tropical Medicine and Hygiene 1992; 95: 432-3.

3. Rajapaksa US, Ihalamulla RL, Karunaweera ND. First report of mucosal tissue localisation of leishmaniasis in Sri Lanka. The Ceylon Medical Journal 2005; 50: 90-1.

4. Rathnayake D, Ranawake RR, Sirimanna G, Siriwardhane Y, Karunaweera N, De Silva R. Co-infection of mucosal leishmaniasis and extra pulmonary tuberculosis in a patient with inherent immune deficiency. International Journal of Dermatology 2010; 49: 549-51.

5. Karunaweera ND, Pratlong F, Siriwardane HV, Ihalamulla
RL, Dedet JP. Sri Lankan cutaneous leishmaniasis is caused by Leishmania donovani zymodeme MON-37. Transactions of the Royal Society of Tropical Medicine and Hygiene 2003; 97: $380-1$.

6. Nawaratna SS, Weligama DJ, Rajapaksha K. Cutaneous leishmaniasis in Sri Lanka: a study of possible animal reservoirs. International Journal of Infectious Diseases 2009; 13: $513-7$.

7. Rosypal AC, Tripp S, Kinlaw C, Hailemariam S, Tidwell RR, Lindsay DS, Rajapakse RP, Sreekumar C, Dubey JP. Surveillance for antibodies to Leishmania spp. in dogs from Sri Lanka. Journal of Parasitology 2010; 96: 230-1.

8. Pratlong F, Dereure J, Ravel C, Lami P, Balard Y, Serres G, Lanotte G, Rioux JA, Dedet JP. Geographical distribution and epidemiological features of Old World cutaneous leishmaniasis foci, based on the isoenzyme analysis of 1048 strains. Tropical Medicine and International Health 2009; 14: 1071-85.

\section{P H K I S Ranasinghe ${ }^{1}$, P H Abeygunasekera ${ }^{2}$, S B Athauda ${ }^{3}$, N V Chandrasekharan ${ }^{4}$, A S V Mendis ${ }^{2}$, C S Hulangamuwa ${ }^{2}$, D R Wickremasinghe ${ }^{1}$}

${ }^{1}$ Department of Parasitology, Faculty of Medical Sciences, University of Sri Jayewardenepura, Sri Lanka, ${ }^{2}$ Teaching Hospital, Anuradhapura, ${ }^{3}$ General Hospital, Vavuniya, ${ }^{4}$ Department of Chemistry, University of Colombo, Sri Lanka.

Correspondence: PHKISR, e-mail: <ishalindra@yahoo.com>. Received 3 January and accepted 26 March 2011. Competing interests: none declared. 